\title{
PRETEXT Stage 4 Hepatoblastoma
}

National Cancer Institute

\section{Source}

National Cancer Institute. PRETEXT Stage 4 Hepatoblastoma. NCI Thesaurus. Code C7142.

An internationally developed presurgical anatomic staging system using imaging techniques: Tumor involves all 4 quadrants; there is no quadrant free of tumor. (from PDQ 2004) 